\title{
Applications of MEMS in Surgery
}

\author{
KEITH J. REBELLO, MEMBER, IEEE
}

Invited Paper

In the past few decades, microelectromechanical systems (MEMS) have found themselves being adopted into a wide variety of fields and disciplines. Recently there has been an increased interest in the use of MEMS for surgical applications. MEMS technology has the potential to not only improve the functionality of existing surgical devices, but also add new capabilities, which allow surgeons to develop new techniques and perform entirely new procedures. MEMS can improve surgical outcomes, lower risk, and help control costs by providing the surgeon with real-time feedback on the operation. This paper discusses the challenges MEMS face in the medical device market along with current applications and future directions for the technology.

Keywords-Medical devices, microelectromechanical systems (MEMS), minimally invasive surgery (MIS), surgical robotics, surgical tools, tactile feedback.

\section{INTRODUCTION}

Microelectromechanical systems (MEMS) is a technology developed from the integrated circuit (IC) industry to create miniature sensors and actuators. Originally these semiconductor processes and materials were used to build electrical and mechanical systems, but have now expanded to include biological, optical, fluidic, magnetic, and other systems as well. The term "MEMS" originated in the United States and typically contains a moving or deformable object. In Europe this technology goes by the name "microsystems technology" or "microstructures technology" (MST) and also encompasses the method of making these devices, which is referred to as micromachining. In Japan and Asia, MEMS are called micromachines when mechanisms and motion are involved.

MEMS devices first were used in medical applications in the early 1970s with the advent of the silicon micromachined disposable blood pressure sensors [1]. Currently MEMS devices own this market and are rapidly expanding into other medical areas. Medical applications of MEMS devices are growing at a compounded growth rate of $11.4 \%$ from

Manuscript received March 9, 2003; revised July 1, 2003.

K. J. Rebello is with the Research Technology Development Center, Applied Physics Lab., The Johns Hopkins University, Laurel, MD 20723 USA (e-mail: keith.rebello@jhuapl.edu).

Digital Object Identifier 10.1109/JPROC.2003.820536

\section{Worldwide Forecast for MEMS in Medicine (Dollars in Millions)}

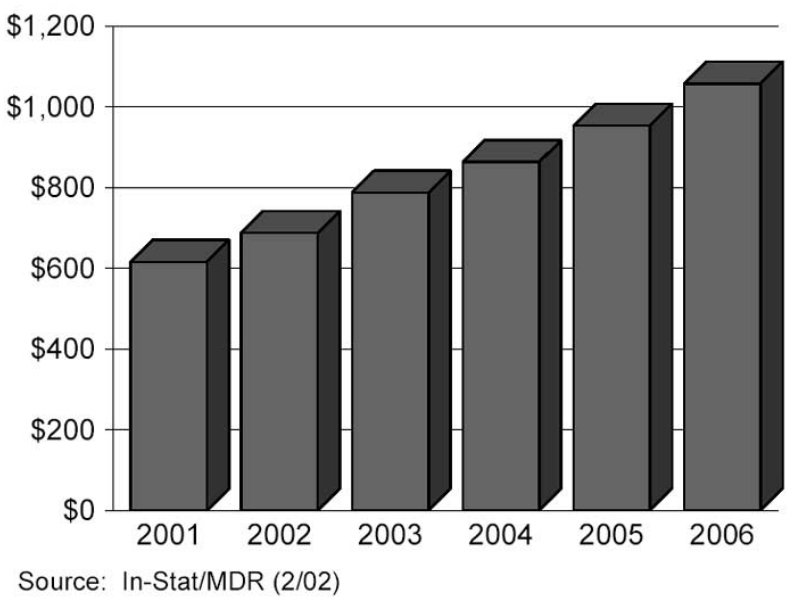

Fig. 1. Worldwide forecast for MEMS in medicine.

$\$ 850$ million in 2003 to over $\$ 1$ billion in 2006 [2] (Fig. 1). The incorporation of MEMS devices on surgical tools represents one of the greatest growth areas. In the surgical field there is an increased need by doctors and surgeons for real-time feedback during operations. MEMS technology can improve surgical outcomes, lower risk, and help control costs by providing the surgeon with real-time data about instrument force, performance, tissue density, temperature, or chemistry, as well as provide better and faster methods of tissue/fluid preparation, cutting, and extraction.

Recently there has been an increase in research activity in surgical applications of MEMS. While not all-inclusive, relevant research is listed by group in Table 1. Despite the large number of research activities, few surgical MEMS devices have made it to mass market. Surgical MEMS devices must deal with all of the challenges that conventional MEMS devices must overcome including manufacturability, integration with electronics and signal processing, reliability, calibration, testing, and packaging. Surgical applications also have additional unique concerns that must be addressed in order for MEMS surgical tools to evolve away from basic research and toward commercialization. 
Table 1 Surgical MEMS Research Activity

\begin{tabular}{|c|c|c|}
\hline Organization & Activity & References \\
\hline Carnegie Mellon University & Endoscopes, Tracking & [30] \\
\hline $\begin{array}{l}\text { Center for Innovative Minimally Invasive } \\
\text { Therapy, Massachusetts General Hospital }\end{array}$ & Minimally Invasive Devices/ Tissue Molds & [6] \\
\hline Cleveland Clinic Foundation & Catheters, Pressure Sensors, Ultrasound Sensors, Opthalmic Devices & {$[15],[16]$} \\
\hline Delft University of Technology & Catheter Pressure, Flow, Gas sensors, Registration & {$[18],[19],[20]$} \\
\hline $\begin{array}{l}\text { Detroit Medical Center/ Wayne State } \\
\text { University }\end{array}$ & Robotic Surgery, Catheters, Flow Sensors, Tactile Feedback, SAW gas sensors & [3] \\
\hline Duke University & Imaging Catheters/Endoscopes & [31],[32] \\
\hline Forschungszentrum Karlsruhe & Catheters & [12] \\
\hline Fraunhoffer Institute & Catheters & [11] \\
\hline ISSYS, Inc. & Catheters, Pressure Sensors & [14] \\
\hline $\begin{array}{l}\text { Lawrence Livermore National Labs/Micrus } \\
\text { Corporation }\end{array}$ & Microgrippers & [10] \\
\hline Nagoya University & Catheters & [25] \\
\hline Olympus Optical Co., Ltd. & Catheters, Endoscopes & [24], [28] \\
\hline Politecnico di Milano & Micropositioners & [21] \\
\hline Scuola Superiore Sant'Anna & Robotic Surgery, Microgrippers, Endoscope, Catheters & {$[4],[5],[61]$} \\
\hline Sensant Corp. & Ultrasound Transducers & [29] \\
\hline Seoul National University & Catheters & [33] \\
\hline $\begin{array}{l}\text { Silex/RADI Medical/ Royal Institute of } \\
\text { Technology }\end{array}$ & Catheter Pressure Sensors & [17] \\
\hline The Pennsylvania State University & Microgrippers & [22],[23] \\
\hline Tohoku University & Catheters & {$[26],[27]$} \\
\hline $\begin{array}{l}\text { University of California, Berkeley/University } \\
\text { of Wisconsin/ Cornell University }\end{array}$ & Ultrasonic Cutting Tools & [9] \\
\hline University of Minnesota & Sensors/Actuators for Cataract Removal & {$[7],[8]$} \\
\hline University of Pisa & Robotic Surgery, Tactile Feedback & [63], [64] \\
\hline University of Virginia/ Setagon Inc. & Stents & [34] \\
\hline University of Washington & Robotic Surgery, Tactile Feedback & [59] \\
\hline Verimetra, Inc. & Surgical Tools, Catheters, Ultrasonic Sensors & $\begin{array}{l}\text { [13], [60], } \\
{[62]}\end{array}$ \\
\hline
\end{tabular}

World Market Share of Minimally Invasive Surgery Products

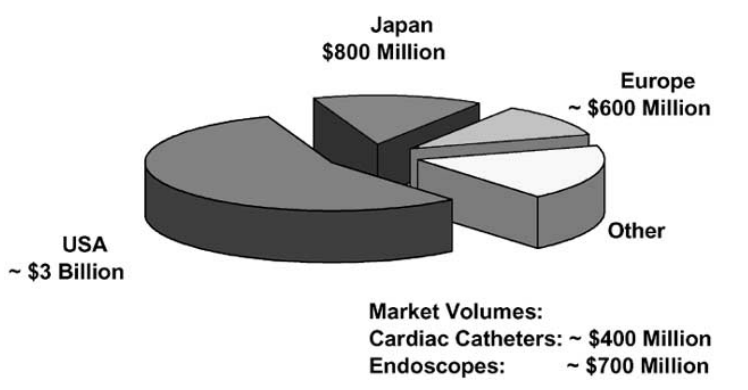

Fig. 2. World market share of MIS products.

\section{PRoduct DEVELopMENT}

When developing a MEMS-based product for the surgical market, it is important to keep the end in mind. The greatest whiz-bang sensor design and fabrication technology will not produce a marketable product if the right application is not chosen. As when building any MEMS product, it is important to evaluate the market for the device, and in this regard the surgical market is a good one. Minimally invasive surgery (MIS) clearly cuts costs and has many other benefits for the surgeon and patient alike. Minimally invasive procedures are growing rapidly, with $40 \%$ of surgeries performed in this manner [35]. The world market share for minimally invasive products is more than $\$ 5$ billion and in the next 15 years $80 \%$ of all surgeries will be done via MIS [36] (Fig. 2). Targeting a disease for which there are a large number of surgical procedures performed, such as heart, lung, cancer, etc., will ensure that the device will receive the required attention from funding sources, researchers, and surgeons. For example, coronary artery disease has a $\sim \$ 120$-billion-dollar economic impact [15], which has fueled research and development of catheter devices.

While it is always important to know your target audience, this is especially important when developing surgical tools. Partnering with surgeons and doctors early in the design process yields a deeper understanding of the problems and issues faced in the operating room. This can shorten the development cycle, as well as result in a tool which better matches the surgeons' needs. These surgeons and doctors will be the end users and clinical champions of the surgical devices and can not only help MEMS engineers to understand what the real problem to be solved is, but also ensure that the device is accepted in the medical community. Interfacing early with the medical community will help to determine if the surgical tool is really needed and if it will be used by surgeons. MEMS engineers should take an honest look to determine if MEMS really is the best choice to solve the problem, or if competing technologies will perform better.

Not only must the surgical tool compete with other devices technically, but it must also compete on a cost basis. This has become more important now that medical providers are under great pressure to reduce costs. Before developing a product it is important to do the math. The device must make a significant impact on a medical procedure to justify any additional cost. In order to do this, MEMS engineers need to 
focus on disruptive technologies which will reduce the skill needed to perform complex procedures and allow them to be performed in more convenient and lower cost settings. The leading medical device companies are often reluctant to incorporate disruptive technology in their products, and tend to favor low-risk incremental improvements. To convince them otherwise takes time, which many young MEMS companies often do not have. Market followers are more likely to take risks and incorporate new technologies in their products in the hope of gaining market share. By teaming with the market followers at an early stage in the development process MEMS companies can overcome the inertia inherent in the medical device industry.

The surgical device market has both low-volume/high value products and high-volume/low-cost devices. While MEMS devices are able to offer competitive advantages due to their batch fabrication, small size, and improved functionality to both these segments, they also have a reputation for being low cost due to their IC roots. The high-volume market is very price sensitive and has low margins but high volumes, which are attractive to MEMS fabrication facilities. The high-value market has high margins and is a good fit for research institutions, research firms, or the medical device companies themselves. The complexities and development of the MEMS fabrication process and other nonrecurring engineering costs as well as fabrication equipment costs need to be factored into the cost of the product. MEMS companies typically cannot sustain themselves in this segment due to the low volumes involved.

\section{A. Biocompatibility and Packaging}

MEMS devices which come into contact with the body must be biocompatible. This adds complexity to the already challenging issue of MEMS packaging. The toxicity and hemocompatibility of the materials used in MEMS are still not understood and more rigorous research studies need to be done. Traditional biocompatibility studies have looked at some MEMS materials in bulk form, but research needs to be carried out on the effect of thin films, as their properties can be different due to their deposition processes. Although preliminary results indicate that there are no cellular toxicity effects and slight increases in clotting with conventional MEMS materials [15], the current approach in using MEMS in vivo relies on isolating MEMS devices from the body by packaging them in biocompatible polymers. These polymers can add to the size of MEMS devices as well as reduce their accuracy. To overcome these issues, nanoparticle coatings and biocompatible polymer micromachining need to be investigated further.

Packaged MEMS devices must be able to survive the sterilization procedures used in the surgical environment. They must withstand exposure to high temperatures and moisture in autoclaves and steam sterilizers. Alternative sterilization methods include ethylene oxide and irradiation. Ethylene oxide is a harsh organic solvent and packages must be made of a compatible material. MEMS devices are inherently radiation hardened, but their associated electronics are not.
They must be specially designed using radiation-hardened IC processes and packages.

\section{B. Regulatory Challenges}

Medical products, of which surgical tools are a subset, are subject to many regulatory controls. The Food and Drug Administration (FDA) and European Community (EC) determine whether a product is fit for sale in the United States and Europe, respectively. Any MEMS devices which have biomedical applications (bioMEMS) such as DNA chips [37], pumps [38], blood glucose detectors [39], catheters [26]-[28], cochlear implants [40], and blood analyzers [41] fall under their jurisdiction. Historically bioMEMS have had design cycles between 5 and 15 years long. Of this time, one to two years have been used for getting the necessary agency approvals. Agencies require that all claims be verified for effectiveness and that the product has proven to be reliable in many sets of clinical trials before they allow a product on the open market. The approval process for disruptive technology can be substantially longer. These agencies also have current good manufacturing practices (cGMP) on how medical devices must be fabricated [42]. These procedures establish a set of standards which aim to ensure that quality products are produced.

Lengthy sets of clinical trials can be avoided if MEMS sensors are applied to existing surgical tools and do not claim to alter the performance. Retrofitting existing surgical tools is the preferred method of entry for MEMS companies because it is the fastest path to market. Retrofitted tools have already been accepted by surgeons who are familiar with their applications and use. Another advantage for MEMS companies is that they themselves do not have to pay for costly clinical trials, which can be avoided by modifying existing tools. If clinical trial cannot be avoided, MEMS companies can partner with device manufacturers to reduce costs and use their expertise in trials.

\section{Design and Fabrication}

Design tools are a challenging area for surgical MEMS. MEMS computer-aided design (CAD) tools are constantly improving, which is helping surgical MEMS to be designed quicker and better, but there is still a disconnect between medical simulation tools and MEMS CAD tools. Design tools which straddle both the MEMS world and medical world are needed to decrease the long time to market of MEMS surgical tools. Recently Freker's research group at Penn State University, University Park, PA, has created software which optimizes the design of MEMS-based minimally invasive surgical tools [21], [22].

Once designed, all MEMS devices must overcome the manufacturability problem. ICs use very similar if not the same technology to make different devices. For example, the same fabrication line that makes the latest microprocessor will often also make graphics chips or digital signal processors. The technology for building MEMS devices, on the other hand, tends to be very application specific and, as such, often has custom materials, fabrication processes, 
and packaging which vary from device to device. This tends to make the conventional MEMS fabrication process more complex and expensive. The geometric constraints, biocompatible material needs, and assembly complexities of surgical MEMS make device fabrication even more challenging.

MEMS devices have traditionally been fabricated on silicon using surface and bulk micromachining technologies. For in-depth coverage of micromachining technologies, the reader is referred to excellent texts by Madou [43] and Kovacs [44]. In surface micromachining, micromechanical structures are fabricated on the surface of a substrate by successively depositing, patterning, and etching selective films. Bulk micromachining relies on wet chemistry or deep reactive ion etching to etch deep structures into the substrate. BioMEMS and in particular microfluidic devices have made use of polymers and plastics as their structural and substrate layers. Typical fabrication techniques for these materials include micromolding, injection molding, and hot embossing. Surgical MEMS devices use these technologies, but also are incorporating newer nonplaner fabrication technologies to better deal with the varied shapes and substrates of surgical instruments.

1) Microelectrodischarge Machining: Microelectrodischarge machining ( $\mu \mathrm{EDM})$ is a form of spark machining used to shape conductive materials such as silicon and metals. Electrodischarge machining erodes material by creating a controlled electric discharge between an electrode and the substrate. It is a noncontact process and there is no direct mechanical cutting force applied to the substrate. Dielectric fluid is used to remove the erosion particles as well as to keep the substrate material from oxidizing. $\mu$ EDMs can be used to make holes, channels gears, shafts, molds, dies, and stents, as well as more complex three-dimensional (3-D) parts such as accelerometers, motors, and propellers [45].

2) Laser Micromachining: Lasers can be used to both deposit and remove material. Laser ablation vaporizes material through the thermal noncontact interaction of a laser beam with the substrate. It allows for the micromachining of silicon and metals as well as materials which are difficult to machine using other techniques such as diamond, glass, soft polymers, and ceramics. Laser direct writing and sintering is a maskless process where a laser beam is used to directly transfer metal materials onto a substrate. This can be used to form metal traces on nonplaner surfaces, which reduces the need for wires on surgical tools [46].

3) Stereolithography: This process generates 3-D structures made out of UV-cured polymers. It is an additive process where complex 3-D structures are made out of thin two-dimensional (2-D) slices of polymer which have been hardened from a liquid bath. Conventional systems were limited in that they were a serial process where only one part could be made at a time. MicroTEC has developed a batch fabricated wafer level process called rapid material product development (RMPD) which is capable of constructing structures out of 100 different materials including plastics, sol-gels, and ceramics [47].

\section{Other Issues}

Once the technology is developed, marketing, sales, clinical trials, and litigation can require more money than product development. It often makes sense for MEMS companies to partner with more experienced medical device companies to bring a product to market. Preferably earlier is better, but care must be taken not to allow medical device companies to steal the MEMS company's intellectual property. Patent litigation is a big concern in the medical field. Medical device makers are notorious for targeting each other with lawsuits. This is a much more aggressive environment than most conventional MEMS companies have experienced. Much money can be spent protecting, defending, and circumventing intellectual property. Additionally, once a product is on the market, companies must be prepared for litigations from patients.

\section{APPLiCATIONS}

Even with the many challenges involved in producing a surgical MEMS device, the potential benefits in terms of improved quality of life and profits from commercialization are pushing development. Now let us look at some application areas in more detail.

\section{A. Surgery}

Much as how MEMS has transformed the sensor industry in the last quarter of the 20th century, surgery has also been advancing. New technologies and procedures have been focusing on minimizing the invasiveness of surgical procedures. To better understand how MEMS devices can improve surgery, it is necessary to look at this evolution in surgery.

Surgery is the treatment of diseases or other ailments through manual and instrumental means. In the past this involved the cutting and sewing of tissue, but advances in surgery have led to greatly reducing or eliminating the invasiveness of surgical procedures. The era of modern surgery began in 1867 with Lister's use of antiseptics in the operating room. Since this time the fundamental tools and techniques used in surgery have not significantly changed. A large incision would be made in the patient allowing the surgeon full access to the surgical area. This is called "open surgery" and is referred to as a first-generation technique. The surgeon has a full and direct view of the surgical area, and is able to put his hands directly into the patient. This enables the surgeon to come into contact with organs and tissue and manipulate them freely. This is the traditional surgical technique and most surgeons were trained in this manner. While the large incision gives the surgeon a wide range of motion to do very fine controlled operations, it causes a lot of trauma to the patient. For example, in a conventional open-heart cardiac operation, the rib cage must be cracked and split, exposing the heart muscle. The invasiveness of the procedure causes a long hospital stay, increasing costs and pain to the patient.

In September 1985, Muhe performed the first laparoscopic cholecystectomy [48], or gall bladder removal surgery with 
a fiber optic scope, and the second generation of surgical procedures was born. This advanced technique is commonly called "minimally invasive surgery," but also goes by other names such as keyhole, micro, telescopic, less invasive, and minimal access surgery. This technique, based on learning from gynecological pelviscopies and arthroscopic orthopedic operations, has subsequently been applied to many other surgical areas such as general surgery, urology, thoracic surgery, plastic surgery, and cardiac surgery. In most of these surgical procedures, the majority of trauma to the patient is caused by the surgeon's incisions to gain access to the surgical site rather than the procedure itself. This is true for cholecystectomies, as $59 \%$ of the postoperative hospital stay is a result of trauma caused by incisions in the abdomen to gain access to the gall bladder instead of the actual removal of the gall bladder [49]. The shorter hospital stay and faster recovery times for the patient reduce the cost of a minimally invasive procedure $35 \%$ compared to its open surgery counterpart.

In a minimally invasive cardiac operation, a few small holes, access points, or ports are punctured into the patient and trocars are inserted. A trocar consists of a guiding cannula or tube with a valve/seal system to allow the body to be inflated with carbon dioxide. This is done so that the surgeon has enough room to manipulate his instruments at the surgical site. An endoscope is inserted into one of the trocar ports to allow the surgeon a view of the surgical site. Various other surgical instruments such as clippers, scissors, graspers, shears, cauterizers, dissectors, and irrigators are mounted on long poles and can be inserted and removed from the other trocar ports to allow the surgeon to perform the necessary tasks at hand.

While MIS has many advantages to the patient, such as reduced postoperative pain, shorter hospital stays, quicker recoveries, less scarring, and better cosmetic results, there are a number of new problems for the surgeon. The surgeon's view is now restricted and does not allow him to see the entire surgical area with his eyes. While the operation is being performed, he must look at a video image on a monitor rather than at his hands. This is not very intuitive and disrupts the natural hand-eye coordination we all have been accustomed to since childhood. The video image on the monitor is also only 2-D and results in a loss of our binocular vision eliminating the surgeon's depth perception. While performing the procedure, the surgeon does not have direct control of his own field of view. A surgical assistant holds and maneuvers the endoscopic camera. The surgeon has to develop his own language to command the assistant to position the scope appropriately, which often leads to orientation errors and unstable camera handling, especially during prolonged procedures. Since the images from the camera are magnified, small motions such as the tremor in a surgical assistant's hand or even their heartbeat can cause the surgical team to experience motion-induced nausea. To combat the endoscopic problems, some surgeons chose to manipulate the endoscope themselves. This restricts them to using only one hand for delicate surgical procedures and makes procedures even more complicated.
The surgeon also loses the freedom of movement he has in open surgery. The trocar ports are fixed to the patient's body walls by pressure and friction forces. This constrains the instrument's motion in two directions and limits the motion of the tip of the instrument to four degrees of freedom (in/out, left/right, up/down, and rotation). The trocars also act as pivot points and cause the surgical instruments to move in the opposite direction to the surgeon's hands. When the surgeon is moving left, the image on the monitor is moving to the right. The amount of this opposite movement also depends on the depth of the introduction of the instrument. Again because of the pivot point, the deeper an instrument is inserted into the body, the more the surgeon's movement is amplified. Even a small movement made by the surgeon on the outside of the patient can translate to a very large movement on the inside of the patient. The seals and valves in the trocars also impede movements, which hinders the smoothness of motions into and out of the patient and greatly reduces the already limited tactile feedback the surgeon experiences. These movement behaviors and lack of tactile feedback are counter to what the surgeon is used to in open surgery and require long training to develop the technical skills to perform these operations.

Performing a minimally invasive procedure has been likened to writing your name holding the end of an eighteen-inch pencil [50]. The surgeon has lost 3-D vision, dexterity, and the sense of touch. The instruments are also awkward, counterintuitive, and restricted in movement. There is no tactile feedback, so the surgeon has no sense of how hard he is pulling, cutting, twisting, suturing, etc. These factors cause a number of adjustments to be made by the surgeon, which requires significant retraining on how to do the procedures in a minimally invasive manner. The difficulties encountered by the surgeon cause degradation in surgical performance compared to open surgery, which limits surgeons to performing only simpler surgical procedures.

In an attempt to address some of these shortcomings and allow the surgeon more control during operations, a third generation of surgical procedures, robotic surgery, was developed. Although these types of procedures are commonly referred to as robotic surgery, the operations themselves are not completely automated and are still carried out by a surgeon. For this reason, robotic surgery is also referred to as computer-aided or computer-assisted surgery.

The technology was originally developed for telerobotic applications in the late 1980s for the Defense Advanced Research Project Administration (DARPA) by researchers at SRI International, Menlo Park, CA. The "surgeon of the future" would allow surgeons from remote command centers to operate on injured soldiers in the battlefield. In 1995, this technology was spun off into a new company named Intuitive Surgical, Mountain View, CA, to commercialize the technology for use in the hospital environment. Near the same time, Dr. Y. Wang was developing robotic technology for NASA to allow surgeons on earth to deal with medical emergencies on the international space station. He formed Computer Motion, Goleta, CA, in 1989. Both of these companies 


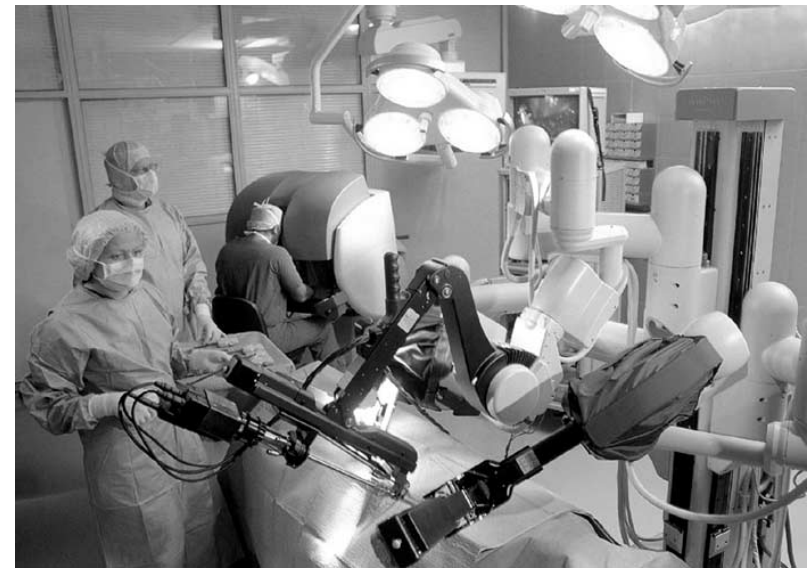

Fig. 3. Intuitive Surgical da Vinci robotic system.

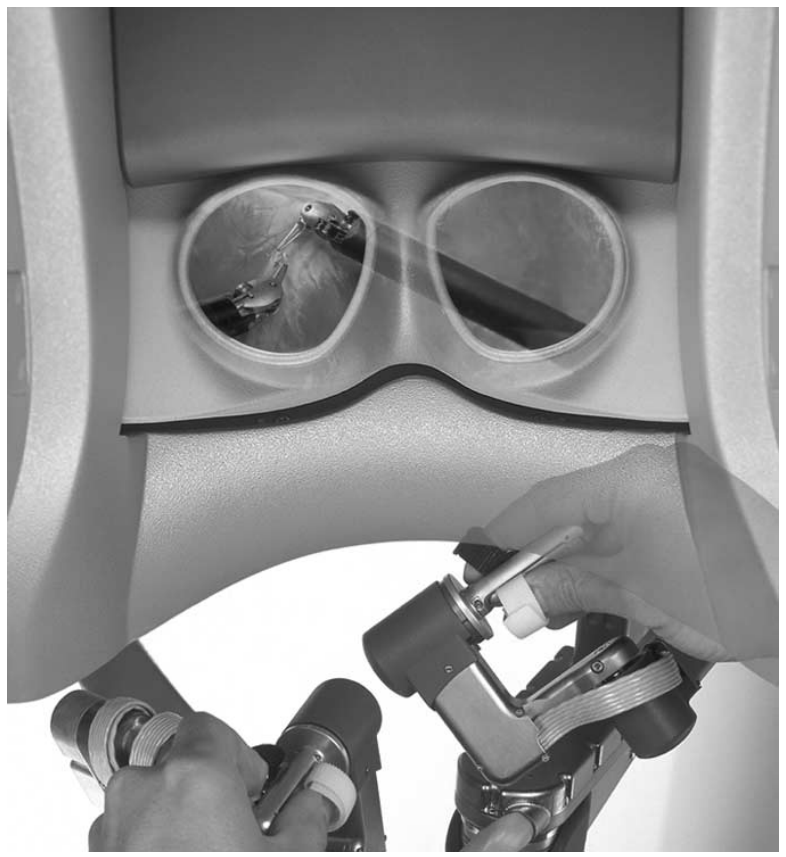

Fig. 4. Intuitive surgical stereo display and joysticks.

helped pioneer the field of robotic surgery and have been involved in multiple patent disputes and intellectual property litigations common in the medical industry. This has resulted in the merger of both these companies.

Current robotic surgery systems have a number of benefits over conventional MIS. Fig. 3 shows an Intuitive Surgical da Vinci robotic system. In this arrangement, the surgeon sits comfortably at a computer console instead of having to stand throughout the entire procedure, which can last up to $5 \mathrm{~h}$. A three-armed robot takes his place over the patient. One arm holds an endoscope while the other two hold a variety of surgical instruments. The surgical team can also look at a video monitor to see what the surgeon is seeing. The surgeon looks into a stereo display and manipulates joystick actuators located below the display. This simulates the natural hand-eye alignment he is used to in open surgery (Fig. 4). Since computers are used to control the robot and are already in the operating room, they can be used to give the

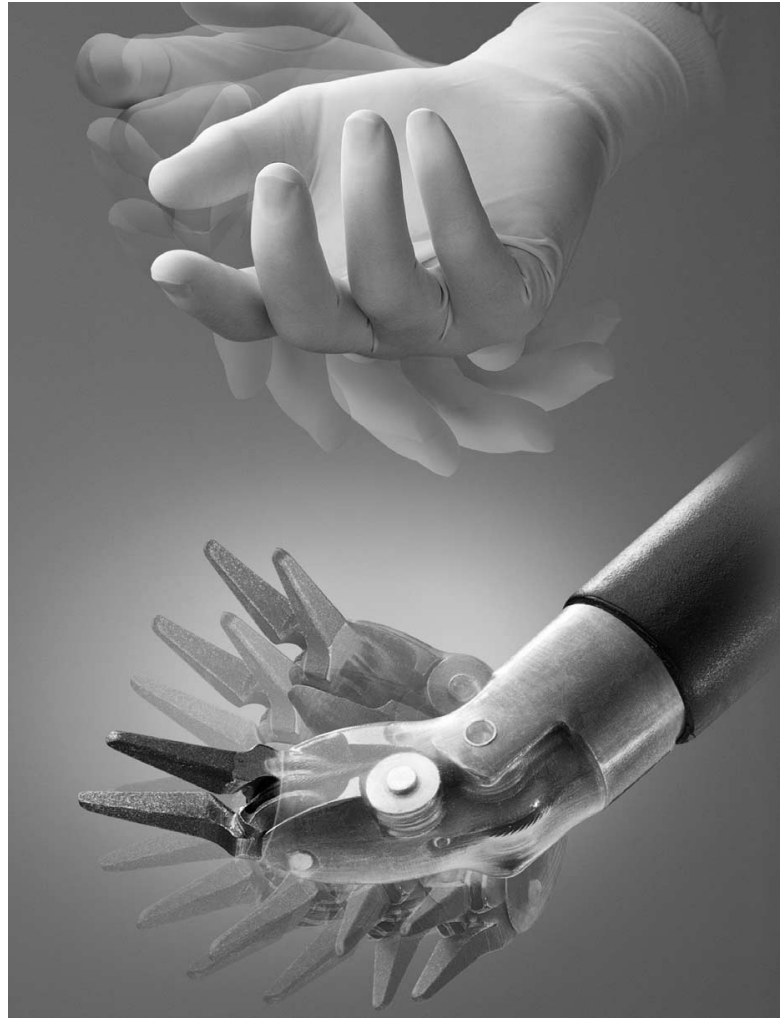

Fig. 5. Multi-degrees-of-freedom end effector.

surgeon superhuman-like abilities. Accuracy is improved by employing tremor cancellation algorithms to filter the surgeon's hand movements. This type of system can eliminate or reduce the inherent jitter in a surgeon's hands for operations where very fine precise control is needed. Motion scaling also improves accuracy by translating large, natural movements into extremely precise micromovements. A wide variety of surgical instruments or end effectors are available including graspers, cutters, cauterizers, staplers, etc. Both companies provide end effectors which have special wristlike joints at their tips, enabling full seven-degrees-of-freedom movements inside the patient (Fig. 5), but still lack tactile feedback. The Intuitive Surgical da Vinci Robot [52], competing Computer Motion Zeus robot [53], and other surgical robots are discussed in more detail in Zenati [54] and Davies [55]. For a deeper background on computer-assisted surgery, the reader is referred to Taylor's classic textbook [51].

These advances allow surgeons to perform more complex procedures such as reconstructive cardiac operations like coronary bypass and mitral valve repair that cannot be performed using minimally invasive techniques. The market for computer-aided surgery was estimated to be $\$ 780$ million in 2003 and to grow to $\$ 2.6$ billion by 2010 [56]. MEMS-based technologies with their small size, improved performance, and ability to interface with existing robotic computer systems will help fuel this growth rate.

\section{B. Tactile Feedback}

As discussed previously, the lack of tactile sensing limits the effectiveness of minimally invasive and robotic surgery. 


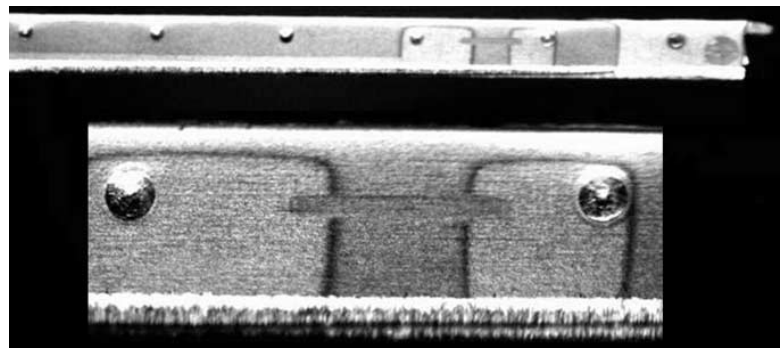

Fig. 6. Strain gauges fabricated on surgical sharps.

For a thorough background on the tactile sensing work during the 1980s and 1990s, the reader is referred to Lee and Nicholls [57], [58]. Recent work in robotic feedback for MIS has concentrated on force feedback techniques using motors and position encoders [21], [59]. The forthcoming Laprotek system from endoVia Medical, Inc., Norwood, MA (formerly Brock Rogers Surgical Inc.), uses sensors on their drive motors to provide tactile clues to the surgeon. In these approaches, the sense element is far removed from the sense area. Verimetra, Inc., Pittsburgh, PA, has developed strain gauge force sensor fabrication technology which uses the surgical tools themselves as a substrate [60]. Prior efforts have focused on fabrication of sensors on silicon, polyimide, or some other substrate followed by subsequent attachment onto a surgical tool with epoxy, tape, or some other glue layer. Attaching a sensor in this manner limits performance, introduces sources of error, limits the sensor's size, and further constrains where the sensor can be placed. Eliminating glue and adhesion layers improves sensitivity and reduces errors due to creep. Fig. 6 shows strain gauges fabricated on surgical sharps. Fig. 7 is a cutaway scanning electron microscopy (SEM) image of a strain gauge and temperature sensor embedded inside of a robotic microforcep. While this microfabrication technology is an improvement in sensor technology, wires are still used to connect the sensor to the outside world. Reliability and the added complexity of adding wires to surgical tools with high degrees of freedom limit the effectiveness of the technology. For MEMS to excel in this area short range, wireless links are necessary.

\section{Tissue Sensing}

The ability to distinguish between different types of tissue in the body is of vital importance to a surgeon. Before making an incision into tissue, the surgeon must identify what type of tissue is being incised, such as fatty, muscular, vascular, or nerve tissue. This becomes more complicated because the composition and thickness of different human tissues varies from patient to patient. Failure to properly classify tissue can have severe consequences. For example, if a surgeon fails to properly classify a nerve and cuts it, then the patient can suffer effects ranging from a loss of feeling to loss of motor control. If a neurosurgeon cuts into a blood vessel while extracting a tumor, severe brain damage may occur. The identification and classification of different types of tissue during surgery, and more importantly during the actual cutting operation, will lead to the creation of smart surgical tools. If a surgical tool senses that it is too close to or about to cut the

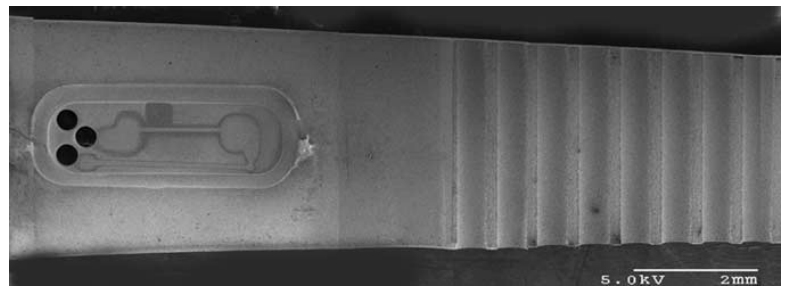

Fig. 7. Strain gauges and temperature sensor embedded in robotic microgripper.

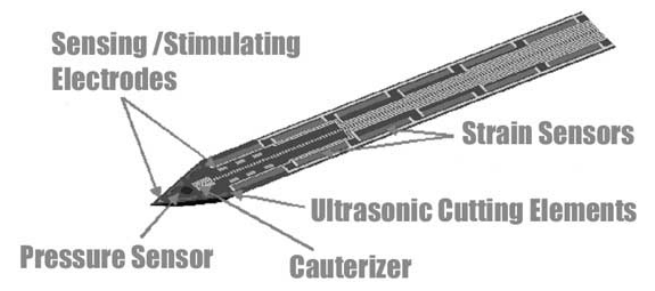

Fig. 8. Data Knife smart scalpel.

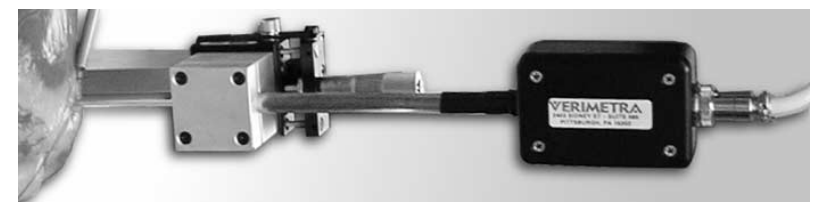

Fig. 9. H-Probe surgical tool for tissue palpation.

wrong type of tissue it can simply turn itself off. This is a disruptive technology area for MEMS.

Verimetra, Inc. has developed a device called the data knife (Fig. 8). It is a scalpel which is outfitted with different strain sensors along the edges of the blade to sense the amount of force being applied. The resistance of the tissue is one of the signals used for classifying tissue. Pressure sensors are used to measure the characteristics of material surrounding the blade. The pressure of the surrounding fluid can be used to help classify the type or location of tissue. Electrodes are used to measure the impedance of different types of tissue as well as being used to identify nerves by picking up their electrical signals. The tool provides the real-time feedback surgeons have been asking for during surgery, and can also be used to record data for later use for tracking purposes.

Sensing the density of tissue can also be used to assist the surgeon in identifying tissue. In open cardiac bypass operations, the surgeons insert their hands inside the body to palpate arteries. For cardiac bypass surgery, surgeons select the bypass location by feeling where the fat and fatty plaque is located in your arteries with their fingers. The lack of tactile feedback in MIS prevents them from using this technique. MEMS devices have been developed for the palpation of tissue using strain gauges [61], diaphragms [62], micropositioners [63], [59], and load cells [64]. One such device is the H-Probe from Verimetra, Inc., shown in Fig. 9. This device uses a density sensor which allows surgeons to assess the quality of the coronary artery by enabling them to palpate vessels during minimally invasive procedures. Blood pressure, pulse, and different kinds of arterial plaque have also been measured [61]. Also of note, although not using 


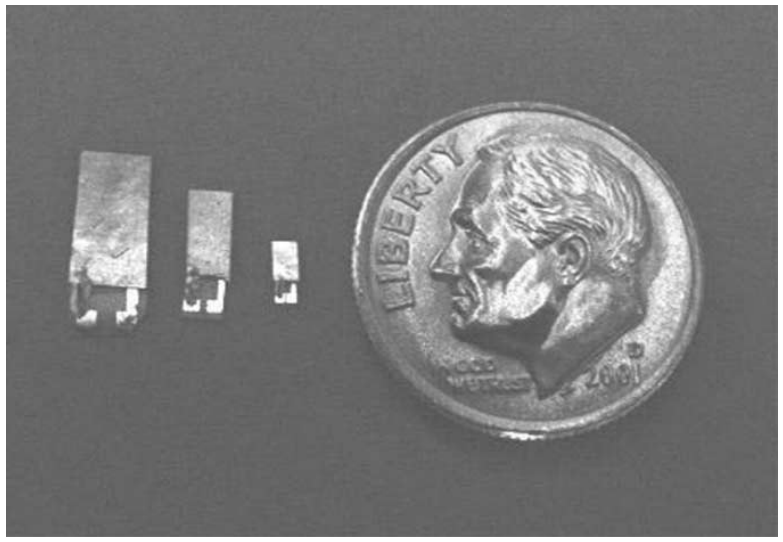

Fig. 10. Ultrasound transducers next to a dime.

MEMS technology, is the work of Hannaford's research group at the University of Washington, Seattle, which has used a force feedback endoscopic surgical grasper (FREG) made from hard disk drive actuators to distinguish between colon, bowel, stomach, lung, spleen, and liver tissue [59].

Piezoelectric transducers can be used to measure density. Macro scale transducers are frequently used in imaging applications to differentiate between tumors, blood vessels, and different types of tissue. These transducers both emit and receive sound waves. By vibrating at a high frequency, sound waves are emitted in the direction of the object of interest. The density of the impinged object can then be measured based on the signal that is reflected back by that object. Sound waves are reflected off the interfaces between different types of tissue and returned to the transducer. Present ultrasound systems tend to be large and are not well suited for incorporation into minimally invasive surgical devices. MEMS technology is well suited for this application and many ultrasonic MEMS sensors have been developed for imaging [16], [29], [31], [33]. MEMS optical mirrors are also used for endoscopic tomography [30], [32].

MEMS ultrasound devices for density measurements from Verimetra, Inc., are shown in Fig. 10. They have been shown to be able to detect the location of bone in tissue and are being applied to atrial fibrillation surgeries. Atrial fibrillation is what causes irregular heartbeats and leads to one out of every six strokes. Drugs can be used to treat this condition, but have dangerous side effects, including causing a switch from atrial fibrillation to the more dangerous ventricle fibrillation. Pacemakers and other electrical control devices can be used, but they do not always work for all patients. The most effective treatment is the surgical MAZE procedure, but it is an incredibly invasive treatment. The patient is put on a heart-lung machine, then the heart is stopped. Next the surgeon takes a scalpel and actually cuts all the way through the heart, making lesions which physically separate the heart muscle. These lesions break the electrical connections in the heart. The heart is then sewn back together. Recently there have been a variety of different methods used to address the problem. Instead of physically cutting all the way through the heart with a scalpel, surgeons are using radio frequency, microwave, cryo, and laser energy to create transmural lesions.
Transmurality means that the lesions go all the way through the tissue, breaking the heart's electrical connections. One of the problems surgeons encounter is to know how deep the ablation is or if it is transmural. If the lesions are not completely transmural or just partially transmural then the undesirable electrical signals may still be transmitted to the heart muscle. MEMS ultrasound technology can be used to measure the transmurality.

Temperature can be used to detect if a surgical device is close to a blood vessel, or if the surgical tool is in a diseased or infected area. Temperature can also be used to monitor the usage of a surgical device, by monitoring the time at which the device is at body temperature. Usage is just one of many areas where auto-ID technologies will benefit surgery [65]. They can be used to make sure that only the correct surgical tool is used for a procedure and if that tool has been properly sterilized. Keeping track of how many times, how long, and what was done with a surgical tool will improve the reliability and effectiveness of surgical procedures and will greatly impact the entire medical industry. MEMS and micromachining technologies will play an important role.

\section{Tracking Systems}

Traditionally a surgeon uses an endoscope in MIS to determine where the surgical instruments are located in the patient. The view the surgeon has of the surgical area is not ideal, and the position of surgical instruments outside of the camera view is not known. Ideally the surgeon would like to know the position and orientation of each of his instruments. Computer-aided surgery has enabled the surgeon to overlay magnetic resonance imaging (MRI) or computed axial tomography (CAT) scan images of the patient with position and orientation data taken during surgery to create 3-D models which the surgeon can use to better visualize the surgical procedure. Computers can be used to simulate the procedure beforehand allowing the surgeon to practice difficult operations ahead of time.

Current technology in this area is predominately optical in nature. Markers are placed on the ends of the surgical instruments which are located outside of the body as well as on specific locations on the patient's body. A computer registers the location of the surgical tools with the reference markers on the patient so that images of the patient's body can be aligned with the surgical tools. This is done through the use of visible and infrared cameras. The tips of the surgical tools which are located inside of the body are then extrapolated. The markers must not interfere with the surgery in any way and, therefore, should be as small and lightweight as possible. While these systems are wireless and do not have cords which can get tangled on the surgeon or on the surgical tools, there must be an unobstructed path from the markers to the camera systems. The surgeon must be careful not to block the markers himself or with other surgical instruments. Precision is compromised because the location of the surgical tips is extrapolated and does not take into account bending of the surgical tools. Markers on the outside of the body do not take into account compression of the tissue. MEMS-based 

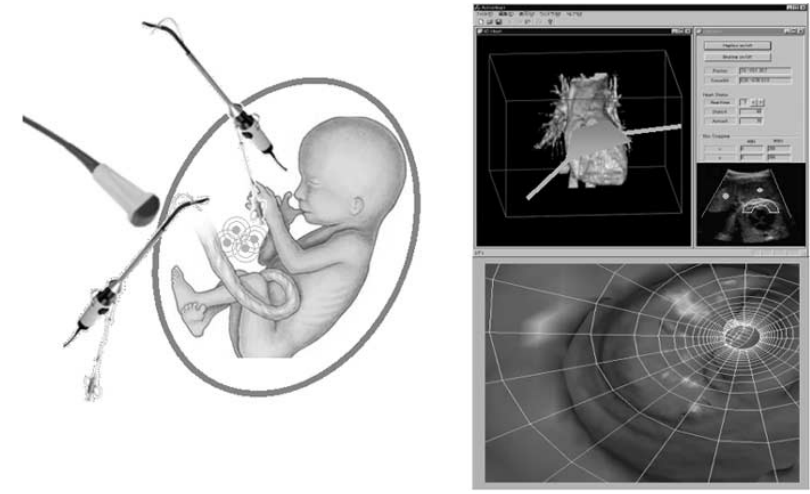

Fig. 11. Ultrasound tracking system for fetal heart surgery. (Courtesy of Carnegie Mellon University, Pittsburgh, PA.)

acoustic tracking systems have been developed to address these issues [20].

Ultrasound sensors can be placed at the tips of tools, thereby eliminating errors from extrapolation. The reference markers can now be placed inside the body, closer to the surgical area so that they are less affected by compression and movement of the patient. Verimetra, Inc., Carnegie Mellon University, Pittsburgh, PA, and Children's Hospital of Pittsburgh, Pittsburgh, PA, are developing ultrasound-tracking technology for fetal surgery where accuracy is of the utmost importance (Fig. 11). Each surgical tool will have up to nine ultrasound transducers arranged in a constellation to determine position and orientation.

Position and orientation can also be detected using accelerometers and gyroscopes. The signal outputs can be integrated to determine or predict the distance traveled by a surgical tool. Conventional MEMS accelerometers have accuracies in the milli-g range (100-1000 times less than the acceleration due to gravity) which are not sufficient for measuring accurately the relatively small displacements made during surgery [66]. More accurate inertial sensors need to be developed before they can be integrated into surgical tools.

\section{E. Eye Surgery}

The leading cause of vision loss in adults over 60 is cataracts. The word cataract comes from the Greek meaning waterfall and was originally thought to be caused by opaque material flowing, like a waterfall, into the eye. The condition is actually caused by the clouding of the eye's intraocular lens. In the eye, light passes through the lens, which focuses it onto the retina. The retina converts the light into electrical signals, which are then interpreted by the brain to give us our vision. The lens is a hard crystalline material made mostly of water and protein. The protein is aligned in such a way to allow light to pass through and focus on the retina. When proteins in the lens clump together, the lens begins to cloud and block light from being focused on the retina. This causes vision to become dull and blurry, which is commonly referred to as a cataract.

Much like other surgery in other parts of the body, cataract surgery has followed down the minimally invasive path for the same benefits. Cataract surgery is one of the earliest known surgical procedures. The earliest evidence is the Sanskrit writings of the Hindu surgeon Susrata dating from the 5th century BC. He practiced a type of cataract surgery known as couching or reclination, in which a sharp instrument was inserted into the eye and the clouded lens was pushed out of the way. This displacement of the lens enabled the patient to see better. Although vision was still blurred without corrective lenses, many famous people underwent this procedure including the artists Michelangelo, Rembrandt, and Renoir. Couching was still performed until the mid-20th century in Africa and Asia.

In 1748, J. Daviel of Paris, France, introduced extracapsular surgery, where the lens was removed from the eye. Later, very thick pairs of glasses were used to focus the light onto the retina and restore sight, but the glasses were cumbersome and caused excessive magnification and distortion.

By 1949, Dr. Harold Ridley of the U.K. used polymethylmethacrylate (PMMA) as the first intraocular lens. He discovered that PMMA was biocompatible with the eye while treating World War II fighter pilots whose eyes were damaged by shattering plastic from their windshields. In the 1960s and 1970s, extracapsular surgery became the preferred treatment. A large incision (10-12 mm) was made in the eye to remove and replace the lens. This procedure minimized problems with image size, side vision, and depth perception, but the large incisions required longer hospitalization, recovery time, and stitches.

Today cataracts are removed with a procedure called phacoemulsication, with $\sim 1.5$ million operations performed yearly. A hollow ultrasonically driven titanium needle is inserted into the anterior chamber of the eye. Ultrasonic energy is then used to liquefy the hard lens, and it is then aspirated out of the eye. A foldable lens made of acrylic or silicone is inserted through a $1-3-\mathrm{mm}$ hole as a replacement. Since the incision size has been reduced compared to conventional extracapsular surgery, hospitalization, general anesthesia, sutures, and bandages have all been eliminated. The reduction in incision size has also reduced the risk of infection and postoperative refractions.

During the procedure the surgeon cannot see directly under the needle as the lens is broken up and aspirated. A thin clear membrane or capsule surrounds the lens. The posterior capsule tissue underneath the lens is very delicate and easily cut compared with the crystalline lens. To prevent the soft underlying tissue from damage requires a skilled surgeon who has performed many procedures. If the posterior capsule is ruptured it can lead to glaucoma, infection, or blindness. As the size of the incision has decreased, heat damage to surrounding tissue from the ultrasonic tip has increased, which can alter the characteristics of the tissue and change its appearance. In addition, positive intraocular pressure must be maintained by balancing the flow of infusion fluid at positive pressure and the aspirated cataract lens fragments. If pressure is not maintained, the anterior chamber can collapse. Pressure is currently maintained by sensors located many feet from the surgical area. This distance creates delays in the feedback loop, which can cause dangerous pressure fluctuations leading to damage to the iris and cornea. 


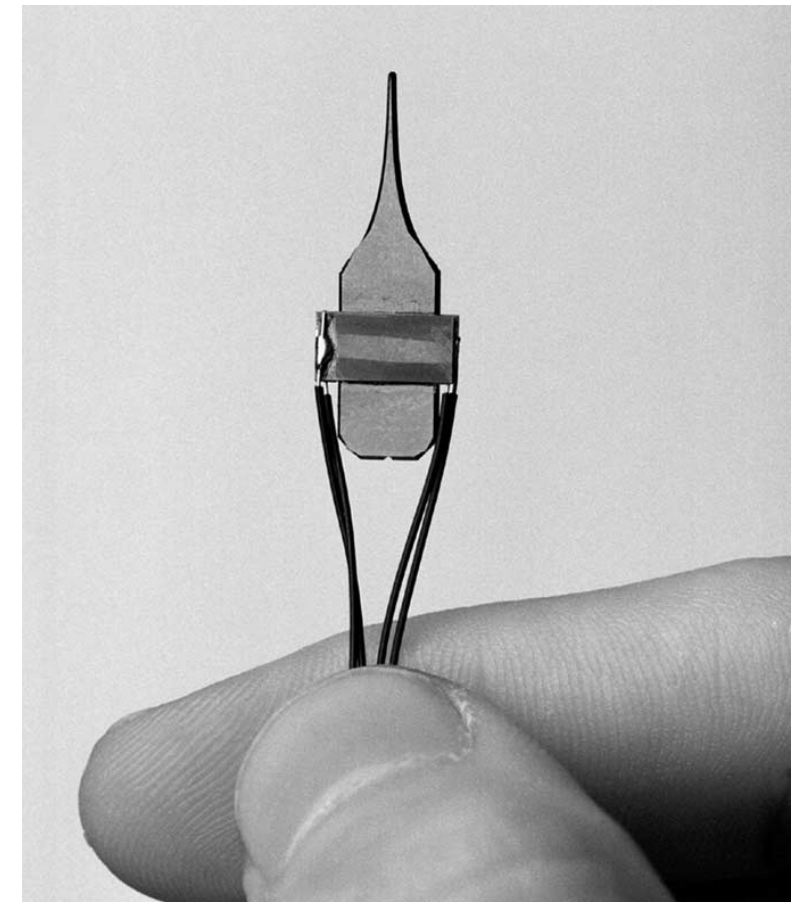

Fig. 12. Ultrasonic phacoemulsifiaction tool. (Courtesy of J. Miller, University of Wisconsin, Madison.)

Recently micromachined silicon ultrasonic surgical tools for phacoemulsifiaction have been developed by Lal's research group [9] (Fig. 12). Piezoelectric material is attached to a micromachined silicon needle. The needle has a fluid channel for aspiration as well as a horn for amplifying the ultrasonic displacement. These silicon devices are able to generate higher stroke velocities and lower heat generation than their conventional titanium counterparts. High levels of integration has been achieved by integrating pressure and flow sensors directly on the needle for maintaining intraocular pressure, reducing delays and making the phacoemulsification procedure safer.

To prevent damage to the posterior capsule, a piezoelectric sensor has been integrated into a phacoemulsification hand piece and undergone clinical trials [8]. The device can determine tissue hardness by measuring the impressed loading on the needle tip or by monitoring the resonant frequency at which the ultrasonic system oscillates. Both of these approaches have proven successful in determining when a hard to soft tissue transition has occurred during a phacoemulsification procedure. This technology enables a surgeon to get real-time feedback on the type of tissue he is cutting, and can be applied to other types of surgical procedures such as tumor extraction as well.

Insertion of a replacement lens requires precise movements by the surgeon. Serious postoperative vision problems may occur if the lens is inserted incorrectly and needs to be removed. Precision piezoelectric micromotors have been developed for intraocular delivery of replacement lenses after cataract removal [7]. These inchworm actuators use a glider and clamp arrangement to generate large forces over small displacements. An electrostatic clamp made of an oxide dielectric layer sandwiched between two silicon wafers layer locks the micromotor in place while a lead zirconate titanate (PZT) actuator generates the force. The inertia of a mass is used to move the clamp. Forces of $3.0 \mathrm{~N}$ and step sizes of $100 \mathrm{~nm}-10$ um have been reported.

In eye surgery there are many times when precision cutting is required. Highly sharpened steel, ceramic, or diamond scalpel blades are used, but are expensive to produce. Disposable silicon micromachined scalpels are an attractive alternative. They can be batch fabricated and sharpened to an atomic edge along their crystal planes. They are already being used at the Fyodorov Eye Care Center, Moscow, Russia, in nonpenetrating deep sclerectomy operations for the treatment of glaucoma [67]. Soon they will be used in other eye operations and eventually migrate to procedures on other parts of the body. Smaller incisions made by sharper blades result in less bleeding. An added advantage of silicon blades is that sensors and electronics can be directly fabricated on them during fabrication. Integrating cauterizing electrodes on the blade itself will prevents the patient from bleeding as well as let the surgeon more clearly see the surgical area.

\section{F. Catheters/Guidewires/Stents}

Cardiac catheterizations can be referred to as a noninvasive surgical procedure although there is some debate between cardiac surgeons and cardiologists as to whether they are indeed surgeries. Specialized tubes or catheters are threaded up through blood vessels in the groin, arm, or neck to an area of the body which needs treatment. The problem is then treated from the inside of the blood vessel. The advantage of these approaches is that the procedures do not require surgical incisions, hospital stays are usually one night or less, and the discomfort and recovery times afterwards are minimal. For patients with more complicated ailments, catheter treatments can be used in combination with minimally invasive or open surgery to give the best possible results at the lowest possible risk. Catheters, guidewires, and stents currently represent the most widespread use of MEMS technology in surgery.

Diagnostic catheterizations are used to measure pressure in different parts of the body, take blood samples, and perform detailed angiograms of the heart can be performed by injecting X-ray dye through the catheters. MEMS pressure sensors are now commonly found on catheter devices, and the most mature MEMS technology in this area and even smaller designs are being sold for placement on guidewires. Fig. 13 shows many pressure sensors made by Silex Microsystems next to a 30-gauge needle. Each sensor is only $100 \mu \mathrm{m}$ thick, $150 \mu \mathrm{m}$ wide, and $1300 \mu \mathrm{m}$ long [17]. MEMS transducers are also starting to be used for intravascular ultrasound imaging [16], [29], [31].

To provide the doctor with more information to make better decisions, additional MEMS sensors are needed to gather additional data for diagnosis and monitoring of procedures as well as for checking results of completed operations. Many other types of MEMS sensors are being researched to measure blood flows, pressures, temperatures, oxygen content, and chemical concentrations for placement on diagnostic catheters [14], [18], [19], [27]. 


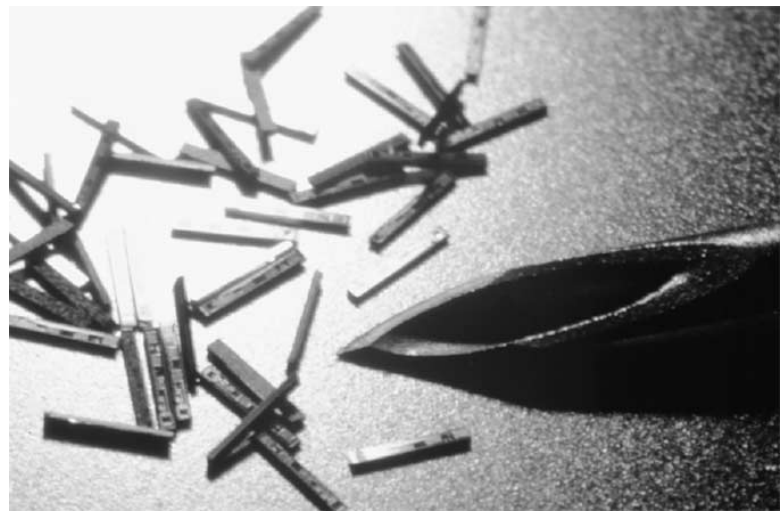

Fig. 13. MEMS pressure sensors and 30-gauge needle. (Courtesy of Silex Microsystems, Jarfalla, Sweden.)

Heart disease continues to be the leading cause of death in the United States. Interventional catheterization is an increasingly more common way to treat blood vessels which have become occluded (blocked) or stenotic (narrowed) by calcified artherosclerotic plaque deposits. Blood vessels which have become occluded or stenotic may interrupt blood flow, which supplies oxygen and cause heart attacks or strokes. Occluded or stenotic blood vessels may be treated with a number of medical procedures including angioplasty and atherectomy. Angioplasty techniques such as percutaneous transluminal coronary angioplasty (PTCA), also known as balloon angioplasty, are relatively noninvasive methods of treating restrictions in blood vessels. A balloon catheter is advanced over a guidewire until the balloon is positioned in the restriction of a diseased blood vessel. The balloon is then inflated compressing the atherosclerotic plaque. Frequently the wall of the vessel is weakened after inflation and a metal stent is expanded and deployed against the plaque. The stent helps keep the vessel open. During an atherectomy procedure, the stenotic lesion is mechanically cut or abraded away from the blood vessel wall using an atherectomy catheter.

MEMS pressure sensors can be used to measure the pressure in the balloons during inflation, to make sure damage due to overinflation is minimized. MEMS temperature sensors can be integrated on catheters and guidewires to determine the location of inflamed plaque. The inflammation causes artery walls in the damaged area to have an increased temperature up to $3{ }^{\circ} \mathrm{C}$ higher than healthy tissue. Approximately $20 \%$ to $50 \%$ of all patients undergoing these therapeutic procedures to clear blocked coronary arteries will suffer restenosis (reblockage) within six months of the initial procedure. Drug-coated stents have significantly lowered these rates and have been approved for use in Europe for a few years. They are expected to be approved in the United States later this year. MEMS laser micromachining technology is used in the fabrication of conventional stents and drug coated stents [68]. Stainless steel micromachining technology has also been developed by Reed's group at the University of Virginia, Charlottesville, for piercing structure drug delivery/gene therapy stents for the treatment of restenosis [34]. There is potentially a large opportunity

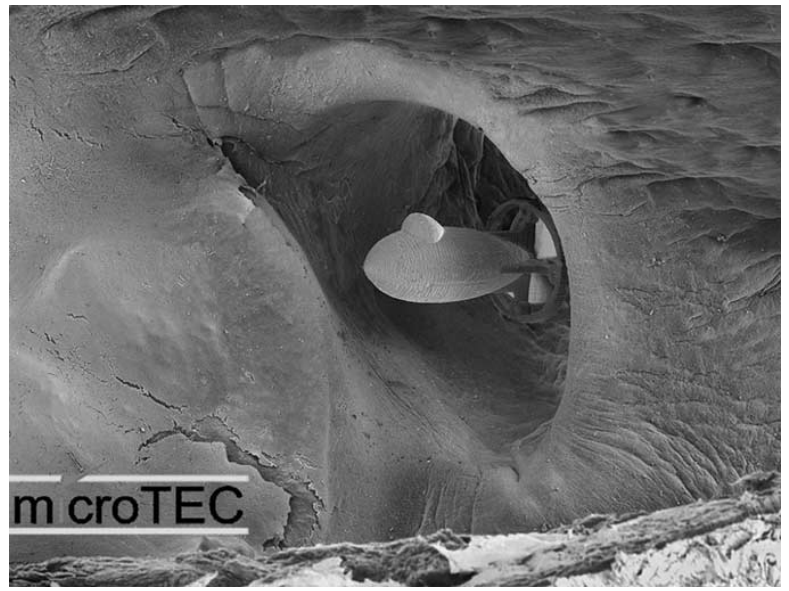

Fig. 14. MEMS propeller submarine — courtesy microTEC.

for MEMS in embedding sensors into stents to create a smart stents, which would be able to alert doctors when restenosis occurs or other problems occur [69]. MEMS rotary cutting devices have been fabricated for atherectomy procedures [12], but are not widely used because cut-up plaque particles can flow downstream and cause strokes.

\section{CONCLUSION}

In 1959 Richard Feynman gave his famous talk "There's Plenty of Room at the Bottom" [70]. In it he talked about being able to put a surgeon in a blood vessel which would be able to look around one's heart. While in the early days of MEMS there was a lot of hype around miniature MEMS submarines [71], Fig. 14 shows a working micropropeller from microTEC. Although we are decades away from having Fanatastic Voyage-like surgical submarines traveling through our arteries, progress is being made toward this end.

There are still many challenges, which have been discussed in this paper, which must be overcome before we will see the widespread commercialization of surgical microsystems. In the next five years we will begin to see the proliferation of MEMS technology into surgery. Initially these new surgical tools will be focused on measuring or detecting a specific parameter, be it pressure, blood flow, velocity, temperature, etc. Sensor systems will continue to be refined and improved. As surgical MEMS technology becomes more mature and established, we will see the integration of multiple sensors on surgical tools. Every time a surgical tool is inserted and removed from the body, there are risks to the patient. To minimize these risks, new technologies will have to be developed to further the miniaturization and creation of multifunctional surgical tools. Power systems will need to be shrunk or eliminated altogether. This will require advances in microbatteries and wireless power transmission schemes. Nanotechnology integrated into MEMS will play an important role leading to new materials and miniature sensor systems. This level of miniaturization will require new MEMS devices which stress the "systems" part of the acronym. Sensors, actuators, embedded control systems, and power systems will have to 


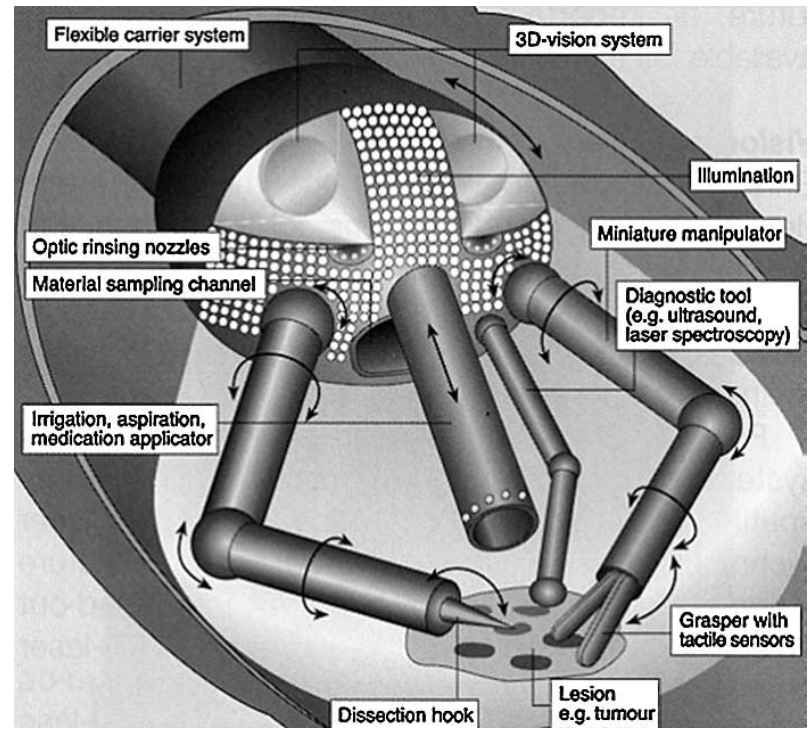

Fig. 15. Highly integrated MEMS probe.

be tightly coupled to each other and the macro world operating room. The result will be smart surgical tools which will communicate with the surgeon, even turning themselves off or resisting the surgeon's movements if they sense danger to the patient. Eventually we will have highly integrated probes, which will do everything a surgeon needs, such as the one shown in Fig. 15 [72]. These tools will fit through a standard 5-mm port and will have built-in 3-D cameras for visualization, biopsy samplers with microfluidic processing capability to do tissue analysis, ultrasound transducers, and tactile sensors for feedback to the surgeon. With the proper funding, collaboration between surgeons and MEMS engineers, and advances in technology, the future looks bright for MEMS applications in surgery.

\section{REFERENCES}

[1] E. Blazer, W. Koh, and E. Yon, "A miniature digital pressure transducer," in Proc. 24th Annu. Conf. Engineering Medicine and Biology, 1971, p. 211.

[2] "BioMEMS: revolutionizing medicine and healthcare," InStat/MDR, Scottsdale, AZ, 2002.

[3] T. Henderson. (2002, Mar.) MEMS robots to give surgeons sense of touch, long-distance. Small Times [Online]. Available: http://www.smalltimes.com/document_display.cfm?document_id= 3236

[4] A. Menciassi, G. Scalari, A. Eisinberg, C. Anticoli, P. Francabandiera, M. C. Carrozza, and P. Dario, "An instrumented probe for mechanical characterization of soft tissues," Biomed. Microdevices, vol. 3, no. 2, pp. 149-156, 2001.

[5] P. Dario, A. Menciassi, C. Stefanini, and D. Accoto, "Miniaturization of biomedical micromachines," in Proc. 2nd Annu. Int. IEEE-EMBS Special Topic Conf. Microtechnology Medicine and Biology, 2002, pp. 291-296.

[6] S. Lalan, I. Pomerantseva, and J. Vacanti, "Tissue engineering and its potential impact on surgery," World J. Surg., vol. 25, pp. 1458-1466, 2001.

[7] D. Polla, A. Erdman, D. Peichel, R. Rizq, Y. Gao, and D. Markus, "Precision micromotor for surgery," in Proc. 1st Annu. Int. IEEE-EMBS Special Topics Conf. Microtechnologies Medicine and Biology, 2000, pp. 180-183.

[8] D. Polla, A. Erdman, W. Robbins, D. Markus, J. Diaz-Diaz, R. Rizq, Y. Nam, H. T. Brickner, A. Wang, and P. Krulevitch, "Microdevices in medicine," Аnnu. Rev. Biomed. Eng., vol. 2, pp. 551-576, 2002.
[9] X. Chen and A. Lal, "Integrated pressure and flow sensor in siliconbased ultrasonic surgical actuator," in Proc. 2001 IEEE Ultrasonics Symp., pp. 1373-1376.

[10] P. Krulevitch, "Polymer-based biomedical microsystems," presented at the BioMEMS 2002 Conf., Boston, MA.

[11] A. Schneider, T. Stieglitz, W. Haberer, H. Beutel, and J. Meyer, "Flexible interconnects for biomedical microsystems assembly," presented at the 34th Int. Symp. Microelectronics IMAPS, Baltimore, MD, 2001.

[12] A. Ruzzu, J. Fahrenberg, M. Muller, C. Rembe, and U. Wallrabe, “A cutter with rotational-speed dependent diameter for interventional catheter systems," in Proc. 11th Annu. Int. Workshop on Micro Electro Mechanical Systems, 1998, pp. 499-503.

[13] K. Rebello, "The use of MEMS in surgery," in BioMEMS Fabrication and Applications of Analytical Devices. Brookline, MA: Knowledge, 2003, ch. 6, pp. 73-88.

[14] J. Foss. (2002, June) ISSYS makes strategic decision to focus on the medical market. Small Times [Online]. Available: http://www.smalltimes.com/document_display.cfm?document_id=3973

[15] S. Roy, "BioMEMS for minimally invasive medical procedures," presented at the BioMEMS 2002 Conf., Boston, MA.

[16] A. Fleischman, R. Modi, A. Nair, G. Lockwood, and S. Roy, "Focused high frequency ultrasonic transducers for minimally invasive imaging," in Proc. 15th Annu. Int. Workshop on Micro Electro Mechanical Systems, 2002, pp. 300-303.

[17] E. Kalvesten, L. Smith, L. Tenerz, and G. Stemme, "The first surface micromachined pressure sensor for cardiovascular pressure measurements," in Proc. 11th Annu. Int. Workshop on Micro Electro Mechanical Systems, 1998, pp. 574-579.

[18] J. F. L. Goosen, D. Tanase, and P. J. French, "Silicon Sensors for use in catheters," in Proc. 1st Annu. Int. IEEE-EMBS Special Topic Conf. Microtechnologies Medicine and Biology, 2000, pp. 152-155.

[19] J. F. L. Goosen, P. J. French, and P. M. Sarro, "Pressure, flow, and oxygen saturation sensors on one chip for use in catheters," in Proc. 13th Annu. Int. Workshop on Micro Electro Mechanical Systems, 2000, pp. 537-540.

[20] F. Tatar, J. Millinger, R. C. Den Dulk, W. A. van Duyl, J. Goosen, and A. Bossche, "Ultrasonic sensor system for measuring position and orientation of laproscopic instruments in minimal invasive surgery," in Proc. 2nd Annu. Int. IEEE-EMBS Special Topic Conf. Microtechnology Medicine and Biology, 2002, pp. 301-304.

[21] A. Pedrocchi, S. Hoen, G. Ferrigno, and A. Pedotti, "Perspectives on MEMS in bioengineering: A novel capacitive position microsensor," IEEE Trans. Biomed. Eng., vol. 47, pp. 8-11, Jan. 2000.

[22] W. Aguilera and M. Frecker, "Design and modeling of an active steerable end-effector," in Proc. SPIE: Smart Structures and Materials 2-Modeling, Signal Processing, and Control in Smart Structures, vol. 4326, 2001, pp. 490-498.

[23] M. Frecker, R. Dziedzic, and R. Haluck, "Design of multifunctional compliant mechanisms for minimally invasive surgery," presented at the Amer. Society Mechanical Engineers Design Engineering Tech. Conf., Pittsburgh, PA, 2001.

[24] H. Miyajima, "Medical and biomedical application of MEMS and optical MEMS," in Proc. IEEE/LEOS Int. Conf. Optical MEMS, 2002, pp. 177-178.

[25] M. Tanimoto, F. Arai, T. Fukuda, H. Iwata, K. Itoigawa, Y. Gotoh, M. Hashimoto, and M. Negoro, "Micro force sensor for intravascular neurosurgery and in vivo experiment," in Proc. 11th Annu. Int. Workshop Micro Electro Mechanical Systems, 1998, pp. 504-509.

[26] K. T. Park and M. Esashi, "An active catheter with integrated circuit for communication and control," in Proc. 12th Annu. Int. Workshop Micro Electro Mechanical Systems, 1999, pp. 400-405.

[27] Y. Haga, T. Mineta, and M. Esashi, "Active catheter, active guidewire and related sensor systems," in Proc. 5th Biannu. World Automation Congress, vol. 14, 2002, pp. 291-296.

[28] H. Takizawa, H. Tosaka, R. Ohta, S. Kaneko, and Y. Ueda, "Developmemt of a microfine active bending catheter equipped with MIF tactile sensors," in Proc. 12th Annu. Int. Workshop Micro Electro Mechanical Systems, 1999, pp. 412-417.

[29] I. Ladabaum, P. Wagner, C. Zanelli, J. Mould, P. Reynolds, and G. Wojcik, "Silicon substrate ringing in microfabricated ultrasonic transducers," in Proc. 2000 IEEE Ultrasonics Symp., vol. 1, 2000, pp. 943-946.

[30] T. Xie, H. Xie, G. Fedder, M. Zeidel, and Y. Pan, "Endoscopic optical coherence tomography with a micromachined mirror," in Proc. 2nd Annu. Int. IEEE-EMBS Special Topic Conf. Microtechnology Medicine and Biology, 2002, pp. 208-211. 
[31] J. Zara, S. Bobbio, S. Goodwin-Johansson, and S. Smith, "Intracardiac ultrasound catheter using a micromachine (MEMS) actuator," in Proc. 1999 IEEE Ultrasonics Symp., vol. 2, 1999, pp. 1173-1176.

[32] J. Zara, J. Izatt, K. Rao, S. Yazdanfar, and S. Smith, "Scanning mirror for optical coherence tomography using an electrostatic MEMS actuator," in Proc. 2002 IEEE Symp. Biomedical Imaging, pp. 297-300.

[33] J. Chang, S. Chung, Y. Lee, J. Park, S. Lee, S. Yang, S. Moon, and D. Han, "Intravascular micro active catheter for minimal invasive surgery," in Proc. 1st Annu. Int. IEEE-EMBS Special Topics Conf. Microtechnologies Medicine and Biology, 2000, pp. 243-246.

[34] M. L. Reed, "Micromechanical systems for intravascular drug and gene delivery," presented at the BioMEMS 2002 Conf., Boston, MA.

[35] M. Mack, "Minimally invasive and robotic surgery," J. Amer. Med. Assoc., vol. 285, no. 5, pp. 568-572, Feb. 7, 2001.

[36] "Micro and nano technologies: A world wide view," Associazione Italiana per la Ricerca Industriale, Rome, Italy, 2001.

[37] G. Lee, C. Lin, F. Huang, C. Liao, C. Lee, and S. Chen, "Microfluidic chips for DNA amplification, electrophoresis separation and on-line optical detection," in Proc. 16th Annu. Int. Workshop Micro Electro Mechanical Systems, 2003, pp. 423-426.

[38] D. Maillefer, S. Gamper, B. Frehner, P. Balmer, H. van Lintel, and P. Renaud, "A high-performance silicon micropump for disposable drug delivery systems," in Proc. 14th Annu. Int. Workshop Micro Electro Mechanical Systems, 2001, pp. 413-417.

[39] J. Kim, B. Kim, E. Yoon, and C. Han, "A new monolithic micro biosensor for blood analysis," in Proc. 14th Annu. Int. Workshop Micro Electro Mechanical Systems, 2001, pp. 443-446.

[40] K. Wise and K. Najafi, "Fully-implantable auditory prostheses: Restoring hearing to the profoundly deaf," in Int. Electron Devices Meeting Dig. (IDEM'02), pp. 499-502.

[41] I. Lauks, "Microfabricated biosensors and microanalytical systems for blood analysis," Acc. Chem. Res., vol. 31, no. 5, pp. 317-324, 1998.

[42] Code Fed. Reg., Oct. 7, 1996. Title 21, pt. 802, 812, 820.

[43] M. Madou, Fundamentals of Microfabrication: The Science of Miniturization, 2nd ed. Boca Raton, FL: CRC, 2002.

[44] G. T. A. Kovacs, Micromachined Transducers Sourcebook. Boston, MA: McGraw-Hill, 2002.

[45] J. Peirs, D. Reynaerts, F. Verplaetsen, M. Poesen, and P. Reneir, "A microturbine made by micro-electro-discharge machining," in Proc. 16th Eur. Conf. Solid-State Transducers, 2002, pp. 790-793.

[46] A. Piqué, C. Arnold, R. Wartena, B. Pratap, B. Shashishekar, K. Swider-Lyons, D. Weir, and R. Kant, "Laser direct-write of miniature sensor and microbattery systems," RIKEN Rev., no. 50, pp. 57-62, Jan. 2003.

[47] R. Götzen, "Growing up, additive processes in MEMS fabrication and packaging," presented at the Machines and Processes Microscale and Meso-scale Fabrication, Metrology and Assembly Conf., Gainesville, FL, 2003.

[48] W. Reynolds Jr., "The first laparoscopic cholecystectomy," J. Soc. Laparoendoscopic Surg., vol. 5, pp. 89-94, 2001.

[49] J. A. Lujan, P. Parrilla, R. Robles, P. Marin, J. A. Torralba, and J. Garcia-Ayllon, "Laparoscopic cholecystectomy vs open cholecystectomy in the treatment of acute cholecystitis," Arch. Surg., vol. 133, pp. 173-175, 1998.

[50] R. Diamiano, "Next up: Surgery by remote control," NY Times, p. D1, Apr. 4, 2000.

[51] R. H. Taylor, S. Lavallee, G. C. Burdea, and R. Mosges, Computer Integrated Surgery: Technology and Clinical Application. Cambridge, MA: MIT Press, 1996.

[52] D. Loulmet, A. Carpentier, N. d'Attellis, F. Mill, D. Rosa, G. Guthart, A. Berrebi, C. Cardon, O. Ponzio, and B. Aupecle, "First endoscopic coronary artery bypass grafting using computer assisted instruments," J. Thoracic Cardiovasc. Surg., vol. 118, no. 1, pp. 4-10, July 1999.

[53] W. Boyd, R. Rayman, N. Desai, A. Menkis, W. Dobkowski, S. Ganapathy, B. Kiaii, G. Jablonsky, F. McKenzie, and R. Novick, "Closedchest coronary artery bypass grafting on the beating heart with the use of a computer-enhanced surgical robotic system," J. Thoracic Cardiovasc. Surg., vol. 120, no. 4, pp. 807-809, Oct. 2000.

[54] M. Zenati, "Robotic heart surgery," Cardiol. Rev., vol. 9, no. 5, pp. $1-8,2001$

[55] B. Davies, "A review of robotics in surgery," in Proc. Inst. Mech. Eng., vol. 214, 2000, pp. 129-140.
[56] "Use of computers in surgery—a multibillion dollar industry," MedMarkets, Foot Hill Ranch, CA, 2002.

[57] H. R. Nicholls and M. H. Lee, "A survey of robotic tactile sensing technology,” Int. J. Robotic Res., vol. 8, no. 3, pp. 3-30, 1989.

[58] M. H. Lee and H. R. Nicholls, "Tactile sensing for mechatronics-A state of the art survey," Mechatronics, vol. 9, no. 1, pp. 1-31, 1999.

[59] J. Rosen, B. Hannaford, M. MacFarlane, and M. Sinanan, "Force controlled and teleoperated endoscopic grasper for minimally invasive surgery-experimental performance evaluation," IEEE Trans. Biomed. Eng., vol. 46, pp. 1212-1221, Oct. 1999.

[60] K. Rebello, K. Lebouitz, and M. Migliuolo, "MEMS tactile sensors for surgical instruments," presented at the 2003 MRS Symp., San Francisco, CA.

[61] A. Menciassi, A. Eisenberg, G. Scalari, C. Anticoli, M. C. Carrozza, and P. Dario, "Force feedback-based microinstrument for measuring tissue properties and pulse in microsurgery," in Proc. 2001 IEEE Int. Conf. Robotics and Automation, 2001, pp. 626-631.

[62] K. Rebello, K. Lebouitz, G. Bononami, E. Di Martino, D. Vorp, and M. Zenati, "MEMS based technology for endoscopic assessment of coronary arterial hardness," presented at the 5th Annu. NewEra Cardiac Care Conf. 2002, Dana Point, CA.

[63] A. Bicchi, G. Canepa, D. De Rossi, P. Iacconi, and E. Scilingo, "A sensorized minimally invasive surgery tool for detecting tissutal eleastic properties," in Proc. 1996 IEEE Int. Conf. Robotics and Automation, pp. 884-888.

[64] E. Scilingo, A. Bicchi, D. De Rossi, and P. Iacconi, "Haptic display able to replicate the rheological behavior of surgical tissues," in Proc. 20th Annu. Int. Conf. IEEE Engineering Medicine and Biology Society, vol. 20, 1998, pp. 1738-1741.

[65] D. Brock, "Smart medicine: The application of Auto-ID technology to healthcare," Auto-ID Center, Mass. Inst. Technol., Cambridge, 2002.

[66] C. Fang and S. Lee, "A research of robotic surgery technique by the use of MEMS accelerometer," presented at the 2nd Joint EMBS/BMES Conf., Houston, TX, 2002.

[67] T. V. Kozlova, N. F. Shaposhnikova, V. B. Scobeleva, and T. V. Sokolovskaya, "Non-penetrating deep sclerectomy: Evolution of the method and prospects for development (review)," Ophthalmosurgery, vol. 3, pp. 39-54, 2000.

[68] Y. P. Kathuria, "Laser microprocessing of stent for medical therapy," in Proc. 1998 Int. Symp. Micromechatronics and Human Science, 1998, pp. 111-114.

[69] P. Goldschmidt-Clermont, D. Kandzari, S. Khouri, and M. Ferrari, "Nanotechnology needs for cardiovascular sciences," Biomed. Microdevices, vol. 3, no. 2, pp. 83-88, 2001.

[70] R. P. Feynman, "There's plenty of room at the bottom," J. Microelectromech. Syst., vol. 1, no. 1, pp. 60-66, Mar. 1992.

[71] A. K. Dewdney, "Nanotechnology: Wherein molecular computers control tiny circulatory submarines," Sci. Amer, vol. 258, pp. 100-103, Jan. 1988.

[72] M. O. Schurr, S.-P. Heyn, W. Ment, and G. Buess, "Endosystems-Future perspectives for endoluminal therapy," Minimally Invasive Therapy Allied Technol., vol. 7, no. 1, pp. 37-42, 1998.

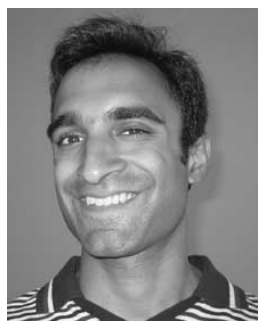

Keith J. Rebello (Member, IEEE) received the B.S. degree in electrical engineering from Virginia Polytechnic Institute and State University, Blacksburg, in 1995 and the M.S. degree in electrical and computer engineering from Carnegie Mellon University, Pittsburgh, PA, in 1997.

$\mathrm{He}$ was with Verimetra, Inc., developing MEMS technology for minimally invasive surgical applications. He is currently a Senior Scientist at the Applied Physics Lab, The Johns Hopkins University, Laurel, MD, where he works in research sensor science. He has several pending patents. His current research focuses on coupling nanotechnology with MEMS, novel materials for MEMS, and developing highly integrated thermal, optical, and biological microsystems.

Mr. Rebello is a member of MRS. 